\title{
The Tunneling of State-Owned Controlling Shareholders and the Incentive of Professional Manager in the Mixed Ownership Reform of Chinese
}

\author{
Chenyuan Zhao, Huan Peng* \\ School of Economics and Finance, Chongqing University of Technology, Chongqing, China \\ Email: *penghuan1234@126.com,68875894@qq.com
}

How to cite this paper: Zhao, C.Y. and Peng, H. (2018) The Tunneling of State-Owned Controlling Shareholders and the Incentive of Professional Manager in the Mixed Ownership Reform of Chinese. Modern Economy, 9, 1839-1852. https://doi.org/10.4236/me.2018.911116

Received: October 19, 2018

Accepted: November 16, 2018

Published: November 19, 2018

Copyright $\odot 2018$ by authors and Scientific Research Publishing Inc. This work is licensed under the Creative Commons Attribution International License (CC BY 4.0).

http://creativecommons.org/licenses/by/4.0/ (c) (i) Open Access

\begin{abstract}
This paper breaks through the relationship between the administrative appointment manager and the State-Owned controlling shareholders, through taking the professional managers with fairness preferences into the State-owned enterprises corporate governance framework. It finds that the equity incentive for the manager will not affect the tunneling behavior of state-owned controlling shareholders in the State-owned enterprise which is administrative, but the equity incentive for the Professional Managers with fairness preferences can restrain the tunneling of State-Owned controlling shareholders to a certain degree. And that a more perfect legal supervision can also restrain the tunneling of State-Owned controlling shareholders. Finally, main strategies for government were suggested, including developing professional manager market, establishing an institution of professional managers, establishing a fair and open competition environment in the market, and making a more perfect legal supervision.
\end{abstract}

\section{Keywords}

The Mixed Ownership Reform of Chinese State Owned Enterprises, Principal-Agent, Equity Incentive, Fairness Preference, Tunneling of Controlling Shareholders

\section{Introduction}

China's mixed ownership has developed for more than 30 years, and the reform of state-owned enterprises' mixed ownership has always been the core of China's economic reform. By joining non-public social capital, state-owned enterprises 
can promote the composition of the main structure of multi-property rights, improve the problems of insider control and supervision failure caused by the "one-share monopoly" of state-owned enterprises, improve the corporate governance mechanism of state-owned enterprises and change the monopoly of state-owned capital [1]. By the mixed ownership reform, it can enhance the influence and control of state-owned capital, play the leading role of state-owned enterprises in the market, induct the healthy development of non-public ownership economy and promote the harmonious development of social economy [2].

However, in the practice of mixed ownership reform of state-owned enterprises, there are many problems that need to be solved. Understanding of mixed ownership in practice is relatively narrow, it simply understood the mixed ownership as the adjustment of ownership structure, and rarely involved in corporate governance mechanism matching reform. Especially, it rarely involves how to improve the efficiency of mixed ownership enterprises, how to protect the rights of medium and small investors, how to standardize enterprise for solving the problems of the governance mechanism design, this is the important reason for not too successful of state-owned enterprises reform China for many years [3]. The western theoretical circle has constructed the corporate governance theory for the shareholding separation enterprises by using the traditional principal-agent theory, which mainly solves the conflict of interests between the shareholders and the business operators, that is, the first type of agency problem [4] [5]. However, the majority of corporate equity in China is not decentralized but highly concentrated. The controlling shareholders have the motivation and power to seek private interests through influencing various decisions of the company, and to tunnel the corporate value or expropriate the interests of medium and small shareholders [6] [7]. In particular, in order to maintain control power, the state-owned capital often choose to hold absolute control over the enterprise, which leads to the widespread phenomenon that the controlling shareholders abuse control and occupy other shareholders' interests [8]. Therefore, businesses in practice generally exists dual principal-agent problem, which is all the shareholders to operator managers and small \& medium-sized shareholders to controlling shareholders [9], the interests conflicts between the small\& medium-sized shareholders to controlling shareholder is growing, this is the second agency problem. The tunneling behavior of controlling shareholders to the interests of minority shareholders has a direct impact on the initiative of private capital to enter into state-owned enterprises, which is resulted in the dilemma of state-owned enterprise mixed ownership reform.

\section{The Principal-Agent Structure Included in the Equity Incentive of Professional Managers}

The enthusiasm of private capital entering to state-owned enterprise is not high, this is caused by many reasons. On the one hand, although the state encourages more non-state capital to enter state-owned enterprises, it may be obstructed by existing state-owned enterprise interest groups in practice. Especially in some 
areas that are competitive, the restriction of market access for a long time has formed large state-owned enterprise interest monopoly groups. Once these competitive areas are opened, it will mean that the monopoly profits of existing interest groups will be largely lost, which is difficult for them to accept [3]. On the other hand, there is huge problem in the governance system of state-owned enterprises in the mixed-ownership reform. Private capital is always worried that in the situation of "one share monopoly" of state-owned capital, once the conflict with state-owned capital occurs, private enterprises will be unable to compete, and the state-owned capital will devour private capital. At the same time, the phenomenon of direct management of enterprises by party and government cadres still exists, which is contradictory to the requirements of the governance and market competition mechanism of mixed ownership enterprises [2]. These operators with administrative background are inevitably represented by the interests of state-owned capital, which can easily cause the board of directors to lose its own functions. In this case, it is also difficult for private capital to block the "hollowing out" behavior of state-owned controlling shareholders, which is not difficult to understand why private capital is not highly motivated to enter into state-owned enterprises.

Many scholars have also studied how to curb the benefit tunneling behavior of controlling shareholders. For example, Duan Y [9] believes that the board structure can restrain the major shareholders' encroachment on the interests of medium and small shareholders from the perspective of board governance. Shi S.P [10] believed that equity checks and balances could also restrain the embezzlement of major shareholders. Dyck and Zingale [11] pointed out that the behavior of major shareholders can be restricted by legal means. In addition, Huang J.B. et al. [12], from the perspective of equity incentive, believe that in the case of "one share monopoly" of state-owned capital, the proprietor is given appropriate equity incentive to become a member of medium and small shareholders, which can effectively connect the interests of medium and small shareholders and operators closely. Chen W.Q and Jia S.H [13] believe that equity incentive can strengthen the synergistic effect of benefit and risk sharing, between shareholders and managers, it can significantly improve enterprise performance, and effectively restrain the first kind agent cost, but it's not significant for the second agency problem (the Tunneling of Controlling Shareholders). These studies all have a premise, that is, the operators are independent professional managers. Actually, in state-owned enterprises, operators are usually officials, this means that they represent the interests of state capital. In such enterprise system, is equity incentive mechanism still effective?

As the controlling shareholders actually control the company, the traditional principal-agent problem between all shareholders and managers has been transformed into the principal-agent problem between controlling shareholders and managers [9]. Therefore, the purpose of giving managers certain equity incentive is to closely connect the interests of operators with operators and small share- 
holders, and depend on operators to control the tunneling behavior of controlling shareholders, thus cause a relationship of supervision and conflict between controlling shareholders and holding managers. The relationship between supervision and conflict is as follows: on the one hand, the controlling shareholders enhance the operating status and value of enterprise through effective supervision of the operators, and then obtain the corresponding capital dividend. On the other hand, the controlling shareholders also use the control rights to infringe the interests of medium and small shareholders including the holding managers, causing the interests conflict between the controlling shareholder and the holding manager [14]. However, in the system of state-owned enterprises, these executives with administrative levels are both "entrepreneurs" and "officials," neither real entrepreneurs \& professional managers nor real officials. The controlling shareholders, managers, and the relations between and among small and medium-sized shareholders as shown in Figure 1(a), enterprise managers and state-owned controlling shareholders are a community of interests, under this circumstances, the enterprise managers wouldn't restrict the behavior of state-owned controlling shareholders even give equity incentive to them. This article will also verify this assumption.

If we want to solve the problem that state-owned controlling shareholders occupy the interests of medium and small shareholders, so as to improve the enthusiasm of private capital into state-owned enterprises, it must remove the obstacles that affect the enthusiasm of private capital. Both state-owned capital holding and state-owned capital equity participation should weaken the government's intervention in enterprise operation and management, give full play to professional managers' ability of operation and management, and enable mixed ownership enterprises to develop healthily according to the requirements of marketization [2]. Therefore, we have constructed a governance framework, as shown in Figure 1(b) relationship structure. Only by cutting off the interest chain between managers and state-controlled shareholders and giving professional managers the mechanism of equity incentive can the interests of operators and medium and small shareholders be truly achieved.

In recent years, a series of game experiments, such as ultimatum game, trust game and gift exchange game, have proved that game participants are limited and self-interested. They not only pay attention to their own benefits, but also tend to pay attention to the fairness of distribution results or process motives [15]. The theoretical model of behavioral economics that describes the equity preference mainly includes the reciprocal model based on motive equity proposed by Rabin [16], and the theoretical model that focuses on the distribution results represented by Fehr and Schmidt [17]. Among them, the F-S model is widely used in the principal-agent theory with strong operability. Foreign scholars such as Itoh [18] and Sabrina Teyssier [19] study the incentive mechanism under the equity preference from the perspective of theory and demonstration. Domestic scholars Li X and Cao G.H [20], Yuan M. et al. [21], Fu Q and Zhu H 
[22] respectively analyzed the equity preference in principal-agent relationship from different dimensions.

Based on the above, this paper, from the perspective of equity incentive, analyzes how the equity incentive mechanism of state-owned enterprises will affect the benefit hollowing out of the state-owned controlling shareholders to medium and small shareholders when managers are directly appointed by the administration in the mixed-ownership reform. Then, by further drawing on the F-S model of equity preference, the paper improved the traditional "rational man" hypothesis and analyzed whether the equity incentive given to professional managers with equity preference could restrain the benefit tunneling behavior of state-owned controlling shareholders.

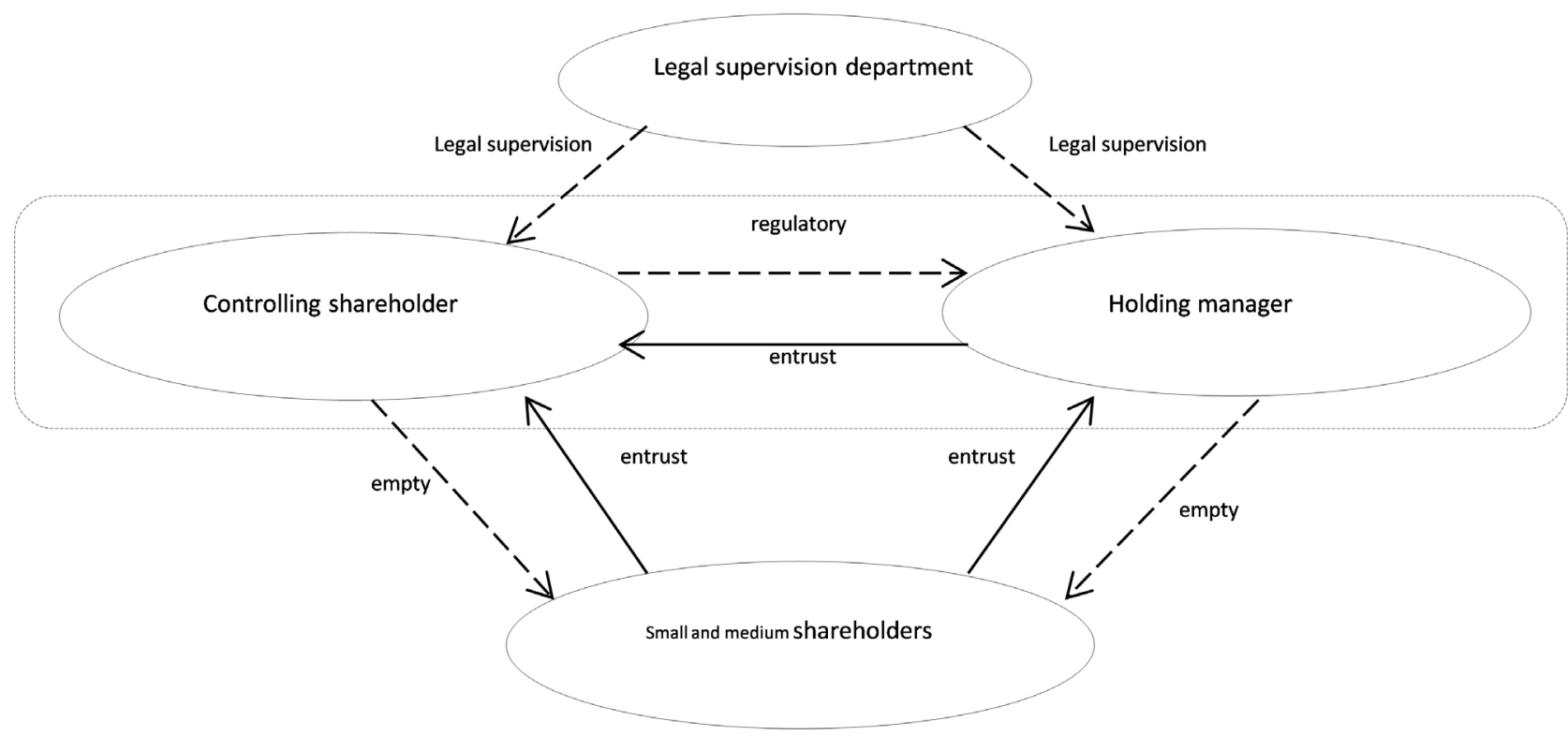

(a)

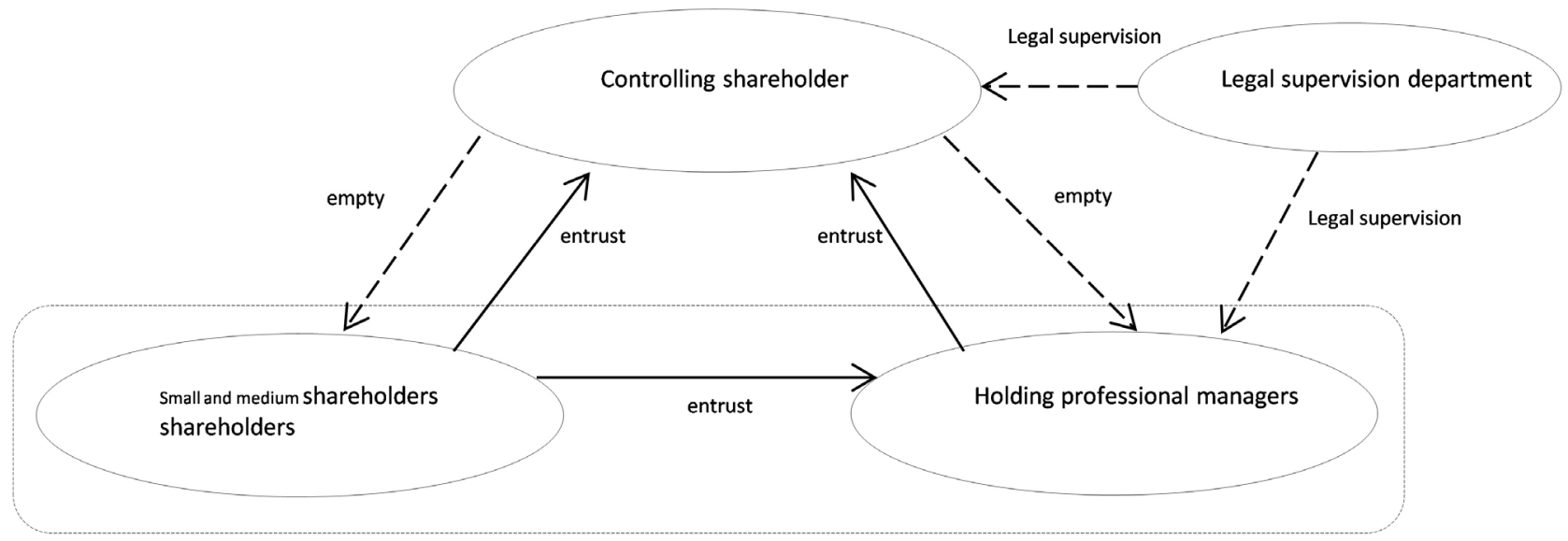

(b)

Figure 1. Relationship structure diagram of state-owned controlling shareholders, medium and small shareholders and shareholding managers. (a) shareholding managers represent the interests of state-controlled shareholders; (b) shareholding professional managers represent the interests of medium and small shareholders. 


\section{Establishment and Solution of the Model}

\subsection{Principal-Agent Model between Shareholding Managers and State-Controlled Shareholders in Administrative State-Owned Holding Enterprises}

The shareholding managers and the minority shareholders entrust the state-owned controlling shareholders to supervise the company. At this time, the minority shareholders and the shareholding managers are the principals, and the state-owned controlling shareholders are the agents. This means that holding managers will take certain risks, while the state-controlled shareholders are not willing to take too much risk. This paper assumes that the shareholding managers are risk-neutral, the state-owned controlling shareholders are risk-averse, and the output function is: $w_{1}=a_{1}+\theta$, where $a_{1}$ is the regulatory effort degree of the state-owned controlling shareholders, $\theta$ is the random variable subject to normal distribution, and it represents the other factors affecting the output. Besides, $E \theta=0, D \theta=\sigma^{2}$. There is a cost for the state-owned controlling shareholders to supervise the enterprise. Managers will not bring additional costs to the "tunneling behavior" of controlling shareholders, because they are communities of interests, and they share the embezzled benefits. The cost function is: $C_{1}=\frac{1}{2} b a_{1}^{2}$, where $b>0$ is the cost coefficient. In addition, the enterprise must compensate the state-owned controlling shareholder for supervising the manager, whose payment contract is: $S_{1}\left(\pi_{1}\right)=\alpha_{1}+\beta_{1} w_{1}, 0<\beta_{1}<1$ is the incentive coefficient. Assume that the state-owned controlling shareholders encroach on the interests of the minority shareholders in the business is $r$, at the same time, the major shareholders need to pay costs. According to the definition of Johnson and others, the behavior of big shareholders occupy legal cost function is: $c=\frac{1}{2} f r^{2}, f$ is the degree of law restricting the expropriation of large shareholders [23]. The actual encroachment gain of the controlling shareholder is: $R_{1}=r-c=r-\frac{1}{2} f r^{2}$, so the actual income of the controlling shareholder is:

$$
\pi_{1}=S_{1}\left(w_{1}\right)+t\left[\pi_{1}-S_{1}\left(w_{1}\right)\right]-C_{1}+\frac{t}{t+\lambda} R
$$

where $t$ is the shareholding ratio of state-owned controlling shareholders and $\lambda$ is the proportion of stock options that given to managers, obviously $0<\lambda<t<1$. Assume that state-owned controlling shareholder has the invariable risk avoidance characteristic. According to the definition of the deterministic equivalent income [24], the deterministic equivalent income of the state-owned controlling shareholder is:

$$
\begin{aligned}
E \pi_{1}-\frac{\rho\left(t \beta_{1}\right)^{2} \sigma^{2}}{2}= & (1-t) \alpha_{1}+\left[t+(1-t) \beta_{1}\right] a_{1}-\frac{1}{2} b a_{1}^{2} \\
& +\frac{t}{t+\lambda}\left(r-\frac{1}{2} f r^{2}\right)-\frac{\rho\left(t \beta_{1}\right)^{2} \sigma^{2}}{2}
\end{aligned}
$$


where $\frac{\rho\left(t \beta_{1}\right)^{2} \sigma^{2}}{2}$ is the risk premium of state-owned controlling shareholder.

As the principal, the net income of the holding manager is:

$$
E \pi_{2}=\lambda\left(w_{1}-S_{1}\left(w_{1}\right)\right)+\frac{\lambda}{t+\lambda} R=\lambda\left(1-\beta_{1}\right) a_{1}-\lambda \alpha_{1}+\frac{\lambda}{t+\lambda}\left(r-\frac{1}{2} f r^{2}\right)
$$

where $\lambda\left(\pi_{1}-S_{1}\left(\pi_{1}\right)\right)$ is the manager's equity income, $\frac{\lambda}{t+\lambda} R$ is the holding manager and the state-controlled shareholder benefit when the integration of interests.

The following model can be obtained:

$$
\begin{aligned}
& \max E \pi_{2}=\lambda\left(1-\beta_{1}\right) a_{1}-\lambda \alpha_{1}+\frac{\lambda}{t+\lambda}\left(r-\frac{1}{2} f r^{2}\right) \\
& I R:(1-t) \alpha_{1}+\left[t+(1-t) \beta_{1}\right] a_{1}-\frac{1}{2} b a_{1}^{2}+\frac{t}{t+\lambda}\left(r-\frac{1}{2} f r^{2}\right)-\frac{\rho\left(t \beta_{1}\right)^{2} \sigma^{2}}{2} \geq \overline{w_{1}} \\
& I C: E \pi_{1}=\max _{a_{1}} E \pi_{1}
\end{aligned}
$$

where $\overline{w_{1}}$ is the net retained income of the state-owned holding shareholders, then the participation constraint condition $I R$ is written as the probability constraint condition: $P\left\{\pi_{1} \geq \overline{w_{1}}\right\}=p_{1}, \quad p_{1}$ is a constant. In consideration of $E \pi_{1}$ and $D \pi_{1}=\left(t \beta_{1}\right)^{2} \sigma^{2}, I R$ can be written as:

$$
P\left\{\frac{\pi_{1}-E \pi_{1}}{t \beta_{1} \sigma} \geq \frac{\overline{w_{1}}-E \pi_{1}}{t \beta_{1} \sigma}\right\}=p_{1}
$$

where $\frac{\pi_{1}-E \pi_{1}}{t \beta_{1} \sigma}$ is subject to the standard normal distribution, and $\Phi\left\{\frac{\overline{w_{1}}-E \pi_{1}}{t \beta_{1} \sigma}\right\}=1-p_{1}, \Phi\{x\}$ is the standard normal distribution function, $\frac{\overline{w_{1}}-E \pi_{1}}{t \beta_{1} \sigma}=Z_{1}$ can be scored through the table. Suppose $Z_{1}<0$, because the $Z_{1}$ is smaller, the greater the risk aversion of the state-owned controlling shareholders, so the probabilistic participation constraints can be obtained:

$$
\text { IR : } t \beta_{1} \sigma Z_{1}+(1-t) \alpha_{1}+\left[t+(1-t) \beta_{1}\right] a_{1}-\frac{1}{2} b a_{1}^{2}+\frac{t}{t+\lambda}\left(r-\frac{1}{2} f r^{2}\right)=\overline{w_{1}}
$$

Therefore, the principal-agent model can be rewritten as:

$$
\begin{aligned}
& \max E \pi_{2}=\lambda\left(1-\beta_{1}\right) a_{1}-\lambda \alpha_{1}+\frac{\lambda}{t+\lambda}\left(r-\frac{1}{2} f r^{2}\right) \\
& I R: t \beta_{1} \sigma Z_{1}+(1-t) \alpha_{1}+\left[t+(1-t) \beta_{1}\right] a_{1}-\frac{1}{2} b a_{1}^{2}+\frac{t}{t+\lambda}\left(r-\frac{1}{2} f r^{2}\right)=\overline{w_{1}} \\
& I C: a_{1}^{*}=\frac{t+(1-t) \beta_{1}}{b}
\end{aligned}
$$

Thus, the results of the above model can be solved:

$$
a_{1}=\frac{1}{b}-\frac{t \sigma\left|Z_{1}\right|}{1-t}, \quad \beta_{1}=1-\frac{b t \sigma\left|Z_{1}\right|}{(1-t)^{2}}
$$


and $r=\frac{1}{f}$

\subsection{Principal-Agent Model between Professional Managers with Fair Preference and State-Owned Shareholders under the Condition of Non Administration}

According to the theoretical model of $F-S$, the participants' fair preference utility mainly comes from three aspects: absolute income utility, jealousy preference utility and pride preference utility. Absolute income utility is measured by absolute income; the jealousy preference utility is negative utility, and the performance is that the net income of other participants is higher than its own net income; Pride preference utility is positive utility, which manifests itself in preference to one's net income higher than the net income of other participants. That is to say, the agent with fair preference utility not only pays attention to his own income, but also pays attention to the income of other participants, and the income gap between him and other participants directly affects the agent's actual income utility.

Based on the $F-S$ theory, the income function of professional managers is modified. Assuming that professional managers represent the interests of minority shareholders as the principal, the controlling shareholder as the agent, as similar as the foregoing assumptions, the state-owned controlling shareholders supervise managers of linear output function is: $w_{2}=a_{2}+\varepsilon$, where $a_{2}$ is the regulatory effort degree of the state-owned controlling shareholders, $\varepsilon$ is the random variable subject to normal distribution, and it represents the other factors affecting the output, and $E \varepsilon=0, D \varepsilon=\sigma^{2}$. There is a cost for the state-owned controlling shareholders to supervise the enterprise. The intervention of professional managers also caused additional costs to the embezzlement behavior of state-owned controlling shareholders. Cost function is: $C_{2}=\frac{1}{2} b a_{2}^{2} r^{2}$, where $b>0$ is the cost coefficient. On the other hand, the enterprise must compensate the state-owned controlling shareholder for supervising the manager, whose payment contract is: $S_{2}\left(w_{2}\right)=\alpha_{2}+\beta_{2} w_{2}, 0<\beta_{2}<1$ is the incentive coefficient. The behavior of big shareholders occupy legal cost function is: $c=\frac{1}{2} f r^{2}, f$ is the degree of law restricting the expropriation of large shareholders [24]. The actual encroachment gain of the controlling shareholder is: $R=r-c=r-\frac{1}{2} f r^{2}$, so the actual income of the controlling shareholder is:

$$
\pi_{1}^{\prime}=S_{2}\left(w_{2}\right)+t\left[w_{2}-S_{2}\left(w_{2}\right)\right]-C_{2}+R
$$

where is the shareholding ratio of state-owned controlling shareholders and $\lambda$ is the proportion of stock options that given to managers, obviously $0<\lambda<t<1$. Assume that state-owned controlling shareholder has the invariable risk avoidance characteristic, and its deterministic equivalent income is: 


$$
\begin{aligned}
E \pi_{1}^{\prime}-\frac{\rho\left(t \beta_{2}\right)^{2} \sigma^{2}}{2}= & (1-t) \alpha_{2}+\left[t+(1-t) \beta_{2}\right] a_{2}-\frac{1}{2} b a_{2}^{2} r^{2} \\
& +\left(r-\frac{1}{2} f r^{2}\right)-\frac{\rho\left(t \beta_{2}\right)^{2} \sigma^{2}}{2}
\end{aligned}
$$

$\frac{\rho\left(t \beta_{2}\right)^{2} \sigma^{2}}{2}$ is the risk premium.

The expected income of the holding manager is: $\pi_{2}^{\prime}=\lambda\left[w_{2}-S_{2}\left(w_{2}\right)\right]-\frac{\lambda}{1-t} r \quad$ According to the $F-S$ model, the actual income of the managers when considering the equity preference is:

$$
\pi_{2}^{\prime}=\lambda\left[w_{2}-S_{2}\left(w_{2}\right)\right]-\frac{\lambda}{1-t} r+k \max \left[\left(\pi_{2}^{\prime}-\pi_{1}^{\prime}\right), 0\right]-k \max \left[\left(\pi_{1}^{\prime}-\pi_{2}^{\prime}\right), 0\right]
$$

$k$ is the equity preference coefficient, and $k \geq 0$ (The preference coefficient of the pride preference and the jealousy preference are both set as $k$ ). The greater the value of $k$, the stronger the equity preference degree of the middleman, the greater the influence of the income gap on the actual net income; Conversely, the smaller the impact. The pride preference $k \max \left[\left(\pi_{2}^{\prime}-\pi_{1}^{\prime}\right), 0\right]$ is positive, the jealousy preference $-k \max \left[\left(\pi_{1}^{\prime}-\pi_{2}^{\prime}\right), 0\right]$ is negative. At this point, the actual net income of the holding manager is:

$$
\begin{aligned}
E \pi_{2}^{\prime}= & (\lambda+k \lambda-k t) a_{2}-(k+\lambda+k \lambda-k t) \beta_{2} a_{2}-(k+\lambda+k \lambda-k t) \alpha_{2} \\
& +\frac{k b a_{2}^{2} r^{2}}{2}-\frac{k+\lambda+k \lambda-k t}{1-t} r+\frac{k f r^{2}}{2}
\end{aligned}
$$

The following model can be obtained:

$$
\begin{aligned}
& \max E \pi_{2}^{\prime}=(\lambda+k \lambda-k t) a_{2}-(k+\lambda+k \lambda-k t) \beta_{2} a_{2}-(k+\lambda+k \lambda-k t) \alpha_{2} \\
& +\frac{k b a_{2}^{2} r^{2}}{2}-\frac{k+\lambda+k \lambda-k t}{1-t} r+\frac{k f r^{2}}{2} \\
& I R:(1-t) \alpha_{2}+\left[t+(1-t) \beta_{2}\right] a_{2}-\frac{1}{2} b a_{2}^{2} r^{2}+\left(r-\frac{1}{2} f r^{2}\right)-\frac{\rho\left(t \beta_{2}\right)^{2} \sigma^{2}}{2} \geq \overline{w_{1}} \\
& I C: \pi_{1}^{\prime}=\max _{a_{2}} \pi_{1}^{\prime}
\end{aligned}
$$

where $\overline{w_{1}}$ is the reserved income of the controlling shareholder of the state. The participation constraint condition $I R$ is written as the probability constraint condition: $P\left\{\pi_{1}^{\prime} \geq \overline{w_{1}}\right\}=p_{2}, \quad p_{2}$ is a constant. In consideration of $E \pi_{1}^{\prime}$ and $D \pi_{1}^{\prime}=\left(t \beta_{2}\right)^{2} \sigma^{2}$, the probability constraint condition can be written as:

$$
P\left\{\frac{\pi_{1}^{\prime}-E \pi_{1}^{\prime}}{t \beta_{2} \sigma} \geq \frac{\overline{w_{1}}-E \pi_{1}^{\prime}}{t \beta_{2} \sigma}\right\}=p_{2}
$$

where $\frac{\pi_{1}^{\prime}-E \pi_{1}^{\prime}}{t \beta_{2} \sigma}$ is subject to the standard normal distribution, and $\Phi\left\{\frac{\overline{w_{1}}-E \pi_{1}^{\prime}}{t \beta_{2} \sigma}\right\}=1-p_{2}, \Phi\{x\}$ is the standard normal distribution function, $\frac{\overline{w_{1}}-E \pi_{1}^{\prime}}{t \beta_{2} \sigma}=Z_{2}$ can be scored through the table. Suppose $Z_{2}<0$, this is because 
the smaller $Z_{2}$, the greater the risk aversion of the state-owned controlling shareholders, so the probabilistic participation constraints can be obtained:

$$
I R: t \beta_{2} \sigma Z_{2}+(1-t) \alpha_{2}+\left[t+(1-t) \beta_{2}\right] a_{2}-\frac{1}{2} b a_{2}^{2} r^{2}+\left(r_{2}-\frac{1}{2} f r_{2}^{2}\right)=\overline{w_{1}}
$$

Therefore, the principal-agent model can be rewritten as:

$$
\begin{aligned}
& \max E \pi_{2}^{\prime}=(\lambda+k \lambda-k t) a_{2}-(k+\lambda+k \lambda-k t) \beta_{2} a_{2}-(k+\lambda+k \lambda-k t) \alpha_{2} \\
& \quad+\frac{k b a_{2}^{2} r^{2}}{2}-\frac{k+\lambda+k \lambda-k t}{1-t} r+\frac{k f r^{2}}{2} \\
& I R: t \beta_{2} \sigma Z_{2}+(1-t) \alpha_{2}+\left[t+(1-t) \beta_{2}\right] a_{2}-\frac{1}{2} b a_{2}^{2} r^{2}+\left(r-\frac{1}{2} f r^{2}\right)=\overline{w_{1}} \\
& I C: a_{2}^{*}=\frac{t+(1-t) \beta_{2}}{b r^{2}}
\end{aligned}
$$

Then:

$$
\begin{aligned}
& \quad a_{2}=\frac{1}{b r^{2}}-\frac{t \sigma\left|Z_{2}\right|}{1-t}-\frac{k t \sigma\left|Z_{2}\right|}{\lambda(1+k)}, \quad \beta_{2}=1-\frac{b r^{2} t \sigma\left|Z_{2}\right|}{(1-t)^{2}}-\frac{k b r^{2} t \sigma\left|Z_{2}\right|}{\lambda(1+k)(1-t)} \\
& \text { and } r^{2}=\frac{(1+k)(1-t)}{\sqrt{b^{2}\left(t \sigma\left|Z_{2}\right|\right)^{2}[k+\lambda+k \lambda-k t]^{2}+b \lambda^{2}(1+k)^{2}(1-t) f}}(r \geq 0)
\end{aligned}
$$

\section{Comparative Analysis}

\subsection{Principal-Agent Model Analysis of the Manager's Administrative Appointment}

Based on 3.1, we have several conclusions as follows:

Conclusion 1: the level of regulatory efforts of state-owned controlling shareholders $a_{1}$ is negatively correlated with their shareholding ratio $t$, cost coefficient $b$ and $\left|Z_{1}\right|$, and it is unrelated to the ratio $\lambda$ of equity incentive for managers.

Proof: $\frac{\partial a_{1}}{\partial b}=-\frac{1}{b^{2}}<0 ; \quad \frac{\partial a_{1}}{\partial t}=-\frac{\sigma\left|Z_{1}\right|}{(1-t)^{2}}<0 ; \quad \frac{\partial a_{1}}{\partial\left|Z_{1}\right|}=-\frac{t \sigma}{(1-t)}<0$

First of all, the effort level of the state-owned controlling shareholders supervising $a_{1}$ is negative related to $t$, the cost coefficient $b$, because the greater the ownership of state-owned controlling shareholders, the stronger it's controlling force on the enterprise, and the cost coefficient is larger also means that the greater the cost of regulatory efforts. These two aspects directly lead to insufficient efforts of state-owned controlling shareholders. This also means that, in the mixed-ownership reform of state-owned enterprises, state-owned capital does not need to pursue absolute control and should adopt the organizational form of relative control as far as possible [3]. Secondly, the level of supervisory efforts of state-controlled shareholders $a_{1}$ has nothing to do with $\lambda$, which indicates that the equity incentives given to managers have no impact on the degree of supervisory efforts of state-controlled shareholders.

Conclusion 2: because of this, the encroachment of state-controlled share- 
holders is only affected by external laws on the protection of minority shareholders' rights and interests. $r=\frac{1}{f} f$ External legal supervision can obviously prevent the state-owned controlling shareholders from encroaching upon the interests of medium and small shareholders. Therefore, a complete legal guarantee can guarantee the entry of private capital into state-owned enterprises. At the same time, for the executives' equity incentive didn't have to the constraint of state-owned controlling shareholders encroach on behavior, in the final analysis is because the manager of the human the administrative appointment of state-owned controlling shareholders, both for the interests of the community here, holding managers think to themselves as "official" official career, not only to supervise state-owned controlling shareholders, will share its encroach on interests.

Proof: $\frac{\partial r}{\partial f}=-\frac{1}{f^{2}}<0$

\subsection{Principal-Agent Model Analysis of Giving Equity Incentive to the Professional Manager with Fair Preferences}

Based on 3.2, we have several conclusions as follows:

Conclusion 3: the level of supervisory efforts of state-owned controlling shareholders $a_{2}$ is positively correlated with the shareholding ratio of professional managers $\lambda$. The larger the shareholding ratio of professional managers, the higher the supervisory effort level of controlling shareholders, and the more obvious the constraint effect of holding professional managers on controlling shareholders.

$$
\text { Proof:; } \begin{aligned}
\frac{\partial a_{2}}{\partial \lambda}= & \frac{b\left(t \sigma\left|Z_{2}\right|\right)^{2}[k+\lambda+k \lambda-k t]+\lambda f}{(1-t) \sqrt{b^{2}\left(t \sigma\left|Z_{2}\right|\right)^{2}[k+\lambda+k \lambda-k t]^{2}+b \lambda^{2}(1+k)^{2}(1-t) f}} \\
& +\frac{k t \sigma\left|Z_{2}\right|}{\lambda^{2}(1+k)}>0
\end{aligned}
$$

Conclusion: 4: the expression of the encroachment of interests of the controlling shareholder can be translated into $r^{21}$

$$
r^{2}=\frac{1-t}{\sqrt{b^{2}\left(t \sigma\left|Z_{2}\right|\right)^{2}\left[\lambda+\frac{1-t}{1+\frac{1}{k}}\right]^{2}+b \lambda^{2}(1-t) f}}
$$

It is easy to see that the embezzlement benefit $r^{2}$ of state-owned controlling shareholders is negatively related to the equity preference $k$ of professional managers, equity proportion of professional managers $\lambda$, external legal constraints $f$ and risk aversion $\left|Z_{2}\right|$.

First of all, the embezzlement benefit $r^{2}$ of state-controlled shareholders is negatively correlated with the fairness preference $k$ and risk aversion of profes${ }^{1}$ For convenience of analysis, we analysis with $r^{2}$ here, and the analytic result is consistent with $\mathrm{r}$. 
sional managers $\left|Z_{2}\right|$. Professional managers with higher equity preference can well curb the encroachment of interests of minority and medium shareholders by state-owned controlling shareholders, and the greater the risk aversion of state-owned controlling shareholders, the more obvious the containment effect.

Secondly, state-owned controlling shareholders encroach on benefit $r^{2}$ is negatively related to the professional manager's stake $\lambda$, this is because the enterprise daily business activities, the professional manager for actual control, familiar with the information of the company, therefore the state-owned controlling shareholders in order to avoid "revenge" from the professional managers, with the increase of professional managers shareholding $\lambda$, the state-owned controlling shareholders will appropriate control their own behavior, thereby avoiding and holding professional managers have direct conflict of interest [13]. This shows that the equity incentive for professional managers achieves the original purpose of curbing the encroachment of the interests of controlling shareholders. Meanwhile, the introduction of equity preference also changes the traditional view, such as literature [14], that the equity incentive for managers does not play a significant role in solving the second type of agent problem.

Thirdly, the embezzlement benefit $r^{2}$ of state-owned holding shareholders is negatively related to external legal constraints $f$, which is consistent with conclusion 2. It verifies again the important role of legal supervision in inhibiting the encroachment of interests of state-owned holding shareholders. Perfect legal guarantee is also the first task to be completed in the mixed-ownership reform of state-owned enterprises.

\section{Conclusion}

The traditional classic principal-agent theory is based on the assumption of "rational man". In practice, it often ignores the non-self-interested psychological tendency of participants, which greatly reduces the explanatory ability of the traditional classic principal-agent theory in the study of corporate governance. Using the theoretical results of behavioral economics, it is closer to reality with the $F-S$ model. In the current state-owned holding enterprises general corporate governance framework, this article introduces fairness preferences of professional managers, breaks through the administrative appoint managers and the interests of the chain between the state-owned controlling shareholders, got an independent professional managers of equity incentive governance framework, to provide a new research perspective about curbing the state-owned controlling shareholders encroach on the interests of behavior. In this paper, firstly, in the administrative state-owned holding enterprises, the equity incentive for managers does not affect the expropriation of the interests of the state-owned holding shareholders to the medium and small shareholders. Secondly, in the de-administration of state-owned holding enterprises, the equity incentive for professional managers with fairness preference can effectively curb the encroachment of interests of state-owned holding shareholders. Thirdly, perfect 
legal supervision also plays an important role in restraining the encroachment of state-owned controlling shareholders' interests.

\section{Fund Support}

Humanities and social sciences research project of Chongqing Education Commission (18SKSJ052).

\section{Conflicts of Interest}

The authors declare no conflicts of interest regarding the publication of this paper.

\section{References}

[1] Huang, S.J. (2014) On the Mixed Ownership Reform of Chinese State Owned Enterprises. Economic Management Journal, No. 7, 1-10.

[2] Yang, H.Y. and Tong, L. (2015) On the Corporate Governance of State Owned Enterprises under the Reform of Mixed Ownership. Macroeconomics, No. 1, 42-51.

[3] Gao, M.H., Du, W.C., Tan, Y.N. and Su, R. (2014) Some Problems about the Development of the Mixed Ownership Enterprises. China Review of Political Economy, 5, 122-139.

[4] Berle, A.A. and Gardiner, C.M. (1932) The Modern Corporation and Private Property. Macmillan, New York, 3: 45.

[5] Jensen, M.C. and Meckling, W.H. (1976) Theory of the Firm: Managerial Behavior, Agency Costs and Ownership Structure. Journal of Financial Economics, 3, 305-360. https://doi.org/10.1016/0304-405X(76)90026-X

[6] Lopez de Silanes, F., Johnson, S., La Porta, R., et al. (2000) Tunneling. American Economic Review and Proceedings, 90, 22-27. https://doi.org/10.1257/aer.90.2.22

[7] Yu, M.G., Xia, X.P. and Wu, S.F. (2004) The New Trend of Corporate Governance Research-The Agency Problem between Controlling Shareholders and Small Shareholders. Foreign Economies and Management, No. 2, 28-32.

[8] Zhao, C.Y. (2005) Development of the Mixed Ownership and Literature Review. Reform of Economic System, No. 1, 48-53.

[9] Duan, Y., Wang, F.S. and Wang, Z.W. (2011) The Model of Board Structure on the Condition of Several Large Shareholders Existing. Nankai Business Review, No. 1, 54-64.

[10] Shi, S.P. (2010) Control Transfer, Excessive Control and Benefits Expropriation of Large Shareholder. Journal of Financial Research, No. 4, 160-176.

[11] Dyck, A. and Zingales, L. (2004) Private Benefits of Control: An International Comparison. Journal of Finance, No. 59, 537-600. https://doi.org/10.1111/j.1540-6261.2004.00642.x

[12] Huang, J.B., Xu, S. and Liu, D.C. (2013) Study on Double Principal-Agent Model Considering Equity Incentive Based on Fairness Preference Theory. Soft Science, 27, 124-129.

[13] Chen, W.Q. and Jia, S.H. (2015) Equity Incentive, Agency Costs and Corporate Performance-Based on the Analysis Framework of Double Principal-Agent Problem. Modern Economic Science, 37, 106-113.

[14] Zhou, R.J. and Gao, K.J. (2012) The Effect of Large Shareholder's Control on Man- 
agers' Ownership Incentive. Accounting Research, No. 5, 50-58.

[15] Cox, J.C. (2000) Trust and Reciprocity: Implications of Game Triads and Social Contexts. University of Arizona Discussion Paper.

[16] Rabin, M. (1993) Incorporating Fairness into Game Theory and Economics. American Economic Review, 83, 1281-1302.

[17] Fehr, E. and Schmidt, K.M. (1999) A Theory of Fairness, Competition and Cooperation. Quarterly Journal of Economics, 114, 817-868. https://doi.org/10.1162/003355399556151

[18] Itoh, H. (2004) Moral Hazard and Other-Regarding Preferences. Japanese Economic Review, 55, 18-45. https://doi.org/10.1111/j.1468-5876.2004.00273.x

[19] Teyssier, S. (2009) Experimental Evidence on Inequity Aversion and Self-Selection between Incentive Contracts. http://ssm.com/abstract=1170767

[20] Li, X. and Cao, G.H. (2008) Research of Incentive Based on Fairness Preference Theory. Journal of Industrial Engineering and Engineering Management, 22, 107-111.

[21] Yuan, M., Lei, Y. and Pu, Y.J. (2011) Incentive Mechanisms and Analysis of Agency Cost Based on Fairness Theory. Journal of Industrial Engineering and Engineering Management, 25, 82-86.

[22] Fu, Q. and Zhu, H. (2014) Incentive Mechanisms Based on Fairness Preference Theory-Give Consideration to Both Vertical and Horizontal Fairness Concerns. Journal of Industrial Engineering and Engineering Management, 28, 190-195.

[23] Johnson, S., Peter, B., Alasdair, B., et al. (2000) Corporate Governance in the Asian Financial Crisis. Journal of Financial Economics, 58, 141-186.

https://doi.org/10.1016/S0304-405X(00)00069-6

[24] Pu, Y.J. (2007) A Model Incorporating Fairness into Principal-Agent: A Contribution from Behavior Economics. Contemporary Finance \& Economics, No. 3, 5-11. 